\title{
ANÁLISE COMBINADA DE SÉRIES TEMPORAIS DE NDVI, TEMPERATURA DO AR E PRECIPITAÇÃO PLUVIAL SOBRE PASTAGEM NATIVA EM SANTA MARIA, RS
}

Andreise Moreira $^{1}$, Tatiana Mora Kuplich ${ }^{1}$, Daniela Wancura Barbieri ${ }^{1}$, Ana Carolina Rodrigues Silveira ${ }^{2}$

${ }^{1}$ Centro Regional Sul de Pesquisas Espaciais/Instituto Nacional de Pesquisas Espaciais/ CRS/INPE ${ }^{2}$ Universidade Federal de Santa Maria/UFSM andreisem@gmail.com

\section{RESUMO}

Séries temporais de NDVI, temperatura do ar e precipitação pluvial sobre pastagem nativa em Santa Maria, RS, cobrindo os anos de 2002 a 2012 foram analisadas através da Transformada de Ondaleta e Análise de Correlação com defasagem de tempo. Resultados apontaram ciclo anual de crescimento da vegetação campestre e maior correlação desta dinâmica de NDVI com a temperatura após um mês de defasagem.

\section{SUMMARY}

NDVI time series, rainfall and air temperature on native pasture in Santa Maria, RS, covering the years 2002 to 2012 were analyzed through the wavelet transform and correlation analysis with time lag. Results showed the annual cycle of grassland vegetation growth and a greater correlation of NDVI dynamic with air temperature after one month lag.

\section{INTRODUÇÃO}

A necessidade premente de informações sobre localização, extensão e dinâmica fenológica de ecossistemas campestres, com vistas à promoção de ações de conservação e manejo (Pillar et al. 2009), tem impulsionado pesquisas com dados de sensoriamento remoto. A disponibilidade de séries temporais de índices de vegetação derivados de dados MODIS (Moderate Resolution Imaging Spectroradiometer), sensor a bordo dos satélites Terra e Aqua possibilita estudos de coberturas vegetais (Pettorelli et al. 2005) e, especificamente, 
campestres, a partir do ano de 2000. Como é conhecida a influência de variáveis meteorológicas sobre a vegetação, a disponibilidade de séries de dados de temperatura do ar e precipitação pluvial, sinaliza a possibilidade de combinação destes.

Este trabalho objetivou a verificação da dinâmica sazonal de pastagem nativa em Santa Maria, RS e estimativa de sua relação com temperatura do ar e precipitação pluvial, utilizando a Transformada de Ondaleta (TO) e Análise de Correlação com defasagem de tempo.

\section{MATERIAL E MÉTODO}

(Adquiriu-se uma série temporal de dados de NDVI (Normalised Difference Vegetation Index) obtido pelo sensor MODIS, através do produto MOD13Q, com resolução espacial de 250m) para o período de janeiro de 2002 a dezembro de 2012, totalizando 253 imagens (23 imagens por ano). A área de estudo compreendeu diversas parcelas experimentais de pastagem nativa utilizada para pecuária, manejada pelo Departamento de Zootecnia da Universidade Federal de Santa Maria (UFSM).

As imagens NDVI foram importadas e processadas no aplicativo SPRING 5.1.8, efetuandose o recorte de acordo com os limites da área de estudo. Foram extraídos valores médios de NDVI, que possibilitaram a geração da TO, por meio da função ondaleta mãe Dog.

Os dados meteorológicos obtidos do INMET (Instituto Nacional de Meteorologia) foram analisados juntamente com os valores de NDVI. Obtiveram-se médias mensais de temperatura do ar e precipitação pluvial para as mesmas datas NDVI e foram estimadas as relações através de Análise de Correlação com defasagem de tempo.

\section{RESULTADOS}

A série temporal (2002 - 2012) NDVI permitiu a identificação da dinâmica fenológica e sazonal da vegetação campestre, com aumento nos valores durante as estações quentes do ano (primavera e verão) e diminuição nas estações mais frias (outono e inverno) (Figura 1A). Como essa área apresenta manejo conservativo, onde o gado pasteja em campo nativo, sem a 
introdução de espécies invernais, é comum o decréscimo de massa foliar verde nos meses frios, com a retomada do vigor vegetal nos meses quentes do ano.

No espectro de potência e espectro de potência global (Figura 1B e 1C), é possível a confirmação da sazonalidade da vegetação campestre, com ciclo anual bem marcado, variando entre 1 e 23 repetições, que caracterizam 1 ano de amostragem.

Para a Análise da Correlação com defasagem de tempo entre NDVI e variáveis meteorológicas, pode-se identificar forte relação com a temperatura do ar (Tabela 1). Nota-se que a resposta da vegetação à variação de temperatura ocorre com mais força após 30 dias de defasagem (Lag1), corroborando a influência desta variável na dinâmica de crescimento vegetal.

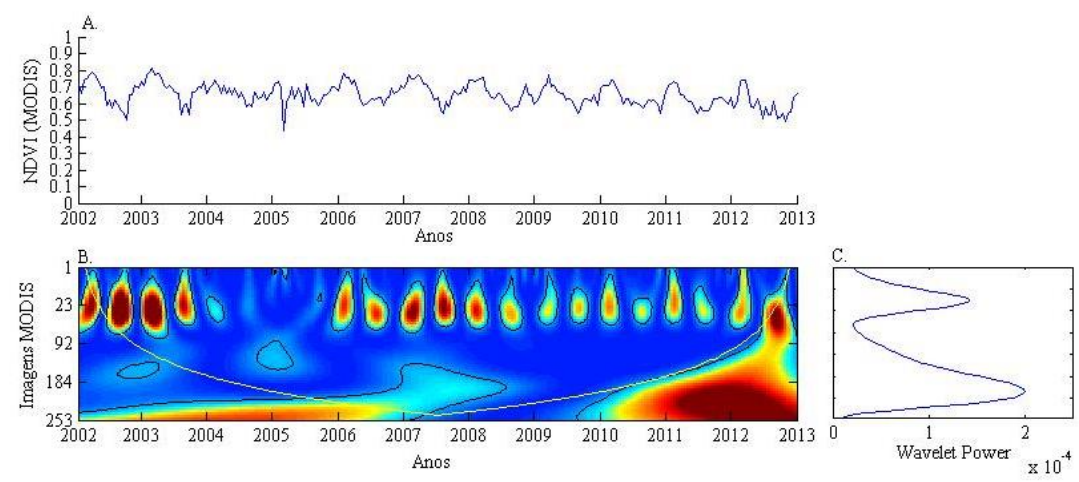

Figura 1. Escalograma da série NDVI para amostra de Santa Maria (A), Espectro de potência (B) e Espectro de potência global $(C)$.

Tabela 1. Correlação de NDVI com dados de Temperatura do ar e Precipitação pluvial para o período de 2002 - 2012 para a amostra de Santa Maria.

\begin{tabular}{|l|l|l|}
\hline \multicolumn{1}{|c|}{ Período de Defasagem } & \multicolumn{1}{|c|}{ Temperatura do ar } & \multicolumn{1}{c|}{ Precipitação pluvial } \\
\hline LAG 0 & 0,64 & 0,11 \\
\hline LAG 1 & 0,65 & 0,16 \\
\hline LAG 2 & 0,51 & 0,21 \\
\hline
\end{tabular}




\section{CONCLUSÕES}

Além da dinâmica fenológica anual de vegetação campestre, é possível com uso da TO identificar variação em períodos distintos durante a série considerada. Estudos futuros analisarão as relações do NDVI com fenômenos climáticos como El Niño e La Niña. Observou-se que há maior correlação dos dados de NDVI com a temperatura do ar e correlação fraca com dados de precipitação pluvial. Pode-se notar que a resposta da vegetação a temperatura ocorre com maior intensidade após 30 dias de defasagem.

\section{AGRADECIMENTOS}

Os autores agradecem à FAPERGS (Fundação de Amparo à Pesquisa do Estado do Rio Grande do Sul) pela bolsa PIBIC para Ana Carolina Rodrigues Silveira.

\section{REFERÊNCIAS}

PETTORELLI, N. et al. Using the satellite-derived NDVI to assess ecological responses to environmental change. Trends in Ecology \& Evolution, v. 20, n. 9, p. 503-510, 2005.

PILlAR, V. D. et al. Campos Sulinos: Conservação e Uso Sustentável da Biodiversidade. Brasília: Ministério do Meio Ambiente, 2009. 